\title{
Hypoxia but not shy-bold phenotype mediates thermal preferences in a threatened freshwater sh, Notropis percobromus
}

\author{
Enders, Eva C.; Wall, Alexander J.; Svendsen, Jon Christian
}

Published in:

Journal of Thermal Biology

Link to article, DOI:

10.1016/j.jtherbio.2019.08.001

Publication date:

2019

Document Version

Peer reviewed version

Link back to DTU Orbit

Citation (APA):

Enders, E. C., Wall, A. J., \& Svendsen, J. C. (2019). Hypoxia but not shy-bold phenotype mediates thermal preferences in a threatened freshwater sh, Notropis percobromus. Journal of Thermal Biology, 84, 479-487. https://doi.org/10.1016/j.jtherbio.2019.08.001

\section{General rights}

Copyright and moral rights for the publications made accessible in the public portal are retained by the authors and/or other copyright owners and it is a condition of accessing publications that users recognise and abide by the legal requirements associated with these rights.

- Users may download and print one copy of any publication from the public portal for the purpose of private study or research.

- You may not further distribute the material or use it for any profit-making activity or commercial gain

- You may freely distribute the URL identifying the publication in the public portal 


\section{Journal Pre-proof}

Hypoxia but not shy-bold phenotype mediates thermal preferences in a threatened freshwater fish, Notropis percobromus

Eva C. Enders, Alexander J. Wall, Jon C. Svendsen

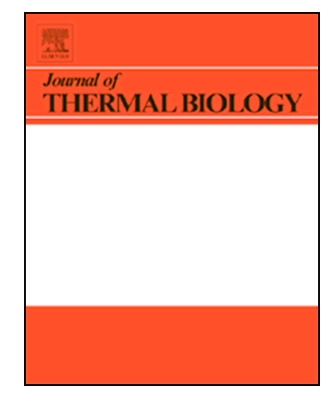

PII: $\quad$ S0306-4565(19)30205-0

DOI: $\quad$ https://doi.org/10.1016/j.jtherbio.2019.08.001

Reference: TB 2395

To appear in: Journal of Thermal Biology

Received Date: 13 April 2019

Revised Date: 30 July 2019

Accepted Date: 4 August 2019

Please cite this article as: Enders, E.C., Wall, A.J., Svendsen, J.C., Hypoxia but not shy-bold phenotype mediates thermal preferences in a threatened freshwater fish, Notropis percobromus, Journal of Thermal Biology (2019), doi: https://doi.org/10.1016/j.jtherbio.2019.08.001.

This is a PDF file of an article that has undergone enhancements after acceptance, such as the addition of a cover page and metadata, and formatting for readability, but it is not yet the definitive version of record. This version will undergo additional copyediting, typesetting and review before it is published in its final form, but we are providing this version to give early visibility of the article. Please note that, during the production process, errors may be discovered which could affect the content, and all legal disclaimers that apply to the journal pertain.

(C) 2019 Published by Elsevier Ltd. 


\title{
Hypoxia but not shy-bold phenotype mediates thermal preferences in a
}

\section{threatened freshwater fish, Notropis percobromus}

\author{
Eva C. Enders ${ }^{1}$, Alexander J. Wall ${ }^{2}$, and Jon C. Svendsen ${ }^{3}$ \\ ${ }^{1}$ Fisheries and Oceans Canada, Freshwater Institute, Winnipeg, Manitoba, Canada \\ ${ }^{2}$ University of Manitoba, Department of Civil Engineering, Winnipeg, Manitoba, Canada \\ ${ }^{3}$ Technical University of Denmark (DTU Aqua), National Institute of Aquatic Resources, \\ Kemitorvet, 2800 Kgs. Lyngby, Denmark
}

(1)

For ectothermic animals, ambient temperature strongly influences developmental growth rate and individual fitness. While many ectotherms live in environments that are spatially heterothermal, the coupling between behavioural phenotypes (e.g., shy or bold behaviour) and thermal preferences remains uncertain. Relative to shy counterparts, bolder phenotypes may exert higher preference for ambient temperatures that are closer to their thermal optimum, thereby accelerating development. In addition, ectotherms should select colder temperatures in low oxygen conditions (hypoxia) according to the oxygen- and capacity-limited thermal tolerance (OCLTT) hypothesis. Using wild caught carmine shiner (Notropis percobromus), this study examined thermoregulatory behaviour in individuals exhibiting consistent behavioural phenotypes along the shy-bold continuum and between ecologically relevant normal oxygen concentration (normoxic) and hypoxic treatments. Furthermore, the behaviour observed in the laboratory was compared to environmental data from the natal stream. Results demonstrated that individual shy-bold behavioural phenotype was consistent before and after a simulated aerial predator attack, indicating consistency of behaviour across situations. Individual preferred and 
avoidance temperatures varied substantially, but were unrelated to shy-bold behavioural phenotypes. In contrast, individual preferred and maximum avoidance temperatures were significantly reduced in hypoxia, consistent with the OCLTT hypothesis. These findings might indicate suppressed development rates in hypoxia, not only by the limited oxygen for aerobic metabolism, but also by the preference for colder water in hypoxia. Furthermore, the tolerated thermal ranges were reduced in hypoxia. Using test conditions confirmed by field data, our study demonstrates the strong influence of oxygen availability on thermoregulatory behaviours and preferences in aquatic environments.

Keywords: boldness, environmental stress; hypoxia, phenotypic variation, thermoregulatory behaviour, temperature. 


\section{INTRODUCTION}

Ambient temperature strongly influences developmental growth rate and individual fitness in ectothermic animals (Guevara-Fletcher et al., 2016). For example, most ectotherms grow faster as ambient temperatures approach their thermal optimum (Elliott and Hurley, 2000). In heterothermal environments, mobile ectotherms may therefore control development rates by actively selecting ambient temperatures. This has been observed in many ectothermic animals, including squamate reptiles (Autumn and De Nardo, 1995), anurans (Lillywhite et al., 1973), and teleosts (Joblin, 1981). However, selecting warmer temperatures has important energetic implications because energy metabolism may increase between 1.5 - to 3.0 -fold for each $10{ }^{\circ} \mathrm{C}$ increase in temperature (Rosewarne et al., 2016). This means that individual ectotherms selecting warmer temperatures not only grow faster (unless they select a temperature, beyond their thermal optimum), they will also need to forage more to counter the elevated energy consumption (Pink et al., 2016). In many animals, foraging is associated with increased risk taking, partly because active vigilance is reduced while searching for food and because food may be more abundant away from the safe locations (Kie, 1999). Variation in behavioural phenotypes, including risk taking and boldness to increase foraging, could therefore be related to preferred temperature in individual ectotherms. It would be consistent with existing theory (Biro and Stamps, 2010; Réale et al., 2010) if bolder phenotypes would accelerate developmental rates by selecting higher temperatures; however, this prediction remains uncertain.

It is increasingly recognized that shy-bold behavioural phenotypes are temporally consistent within individuals. Bell et al. (2009) reviewed data across invertebrates and vertebrates and found that roughly $35 \%$ of the variation among individuals in behaviour is attributed to individual differences. In particular, many studies have revealed a continuum in 
behavioural phenotypes where some individuals within a population are consistently bolder and more risk-taking, while other individuals are consistently shyer and avoid risk (Watanabe et al., 2012; Massen et al., 2013; Andersen et al., 2015). Importantly, elevated boldness is associated with increased foraging success in many animals (Short and Petren, 2008; Carter et al., 2010, 2013; Biro et al., 2014). For example, in the three-spined stickleback (Gasterosteus aculeatus), a bold behavioural phenotype often means better access to food and faster growth rates compared to a shy phenotype (Ward et al., 2004).

Behavioural phenotypes may not only be repeatable across time, but may also be repeatable across different contexts (Bell, 2007; Mazué et al., 2015). Such behavioural syndromes (Andersen et al., 2015) may preclude optimal behaviours (Conrad et al., 2011) and constrain evolutionary responses (Dochtermann and Dingemanse, 2013). However, after losing fights, bold individuals may adjust their behaviour and exhibit less bold traits, as observed in rainbow trout (Oncorhynchus mykiss) (Frost et al., 2007). Similarly, habitat variables and risk of predation may affect shy-bold behavioural phenotypes in killifish (Poecilia vivipara) (SommerTrembo et al., 2017) suggesting that some individual fish are displaying behavioural plasticity by adjusting behaviours to match the surrounding environment (Wong and Candolin, 2015).

Whether bold fish remain bold following a predator attack has been the subject of few studies (Pellegrini et al., 2010; Brown et al., 2013).

Behaviours may be coupled with physiological traits in individual animals (Carter et al., 2013). For example, intraspecific variation in schooling (Killen et al., 2012), migration (Poulsen et al., 2010; Boel et al., 2014), and foraging (Breau et al., 2011) behaviours may be explained by physiological traits. However, a coupling between physiological traits and behavioural phenotypes is not always obvious and may only be revealed when animals are exposed to an 
environmental stressor, including hypoxia (Killen et al., 2013; Svendsen et al., 2014; Behrens et al., 2018). For example, using European seabass (Dicentrarchus labrax), Killen et al. (2012) demonstrated links between physiological traits and behavioural phenotypes in individuals, but only when the environmental oxygen saturation was reduced to $20 \%$ air saturation $\left(\mathrm{O}_{2 \text { sat }}\right)$.

Variation in environmental oxygen content is an important determinant of aerobic scope in most aquatic ectotherms (Svendsen et al., 2014; Rosewarne et al., 2016). The oxygen- and capacity-limited thermal tolerance (OCLTT) hypothesis posits that thermal tolerance is determined by the aerobic scope (Pörtner, 2010; Pörtner and Peck, 2010). Thus, a decline in aerobic scope is correlated with a decline in thermal tolerance, suggesting that thermal tolerance is reduced in ectotherms subjected to environmental hypoxia (Pörtner, 2010; Pörtner et al., 2017). In relation to climate change, the OCLTT hypothesis may explain responses of aquatic ectotherms to variation in temperature. For example, Pörtner and Knust (2007) revealed correlations between laboratory measurements of aerobic performance, thermal tolerance, growth rate, and local abundance of a wild population of the marine eelpout Zoarces viviparous. Yet, the OCLTT hypothesis remains controversial and has been questioned by several recent studies (Clark et al., 2013; Jutfelt et al., 2018). Jutfield et al. (2018) highlighted a range of outstanding issues with the hypothesis and outlined difficulties associated with tests of the hypothesis.

Here, we study thermoregulatory behaviour of a small cyprinid, the carmine shiner Notropis percobromus (Cope 1871), a species listed as Threatened under the Canadian Species at Risk Act (SARA; Fisheries and Oceans Canada, 2018). Given the protection status, this study makes an important contribution to addressing the species' recovery. The carmine shiner occur in the Birch River in Eastern Manitoba, Canada. Previous studies have indicated that the oxygen 
saturation of the river may drop to low levels $\left(0.7 \mathrm{mg} \cdot 1^{-1}\right.$; equivalent to $\left.5 \% \mathrm{O}_{2 \mathrm{sat}}\right)$, particularly during summer, presumably affecting fish movements (Poulsen et al., 2011). We tested the following hypotheses: (1) individual shy-bold behavioural phenotype is consistent across time as indicated by consistent rating along the shy-bold continuum; (2) diversity in behavioural phenotype co-varies with thermoregulatory behaviour, such that shy-bold phenotype predicts thermoregulatory behaviour; and (3) individuals exposed to hypoxia would exhibit lower avoidance temperatures and reduced preferred temperatures relative to individuals in normoxia, consistent with the OCLTT hypothesis. The hypoxic level was selected according to measures of oxygen content in the field.

\section{METHODS}

Environmental variables in the field

Water temperature $\left({ }^{\circ} \mathrm{C}\right)$ and oxygen saturation $\left(\mathrm{O}_{2 \mathrm{sat}}\right)$ were logged hourly in the Birch River, Manitoba, Canada where carmine shiner (Notropis percobromus) occur. These environmental variables were measured in the field to select a relevant hypoxic level for the laboratory study and collect data in an ecologically relevant context. Temperature was measured over one year, while $\mathrm{O}_{2 \text { sat }}$ was measured over two weeks in September. Temperature was logged using HOBO sensors (model U20-001-01; to nearest $0.01{ }^{\circ} \mathrm{C}$; Onset, Bourne, MA, USA), whereas $\mathrm{O}_{2 \text { sat }}$ was logged using Oxyguard sensors (model DO-1050; accuracy: $\pm 1 \% \mathrm{O}_{2 \text { sat }}$; RBR Ltd., Kanata, ON, Canada).

Water temperature and $\mathrm{O}_{2 \text { sat }}$ were logged at four and three different river locations and covered 52 and $40 \mathrm{~km}$ river $\mathrm{km}$, respectively. At each location, loggers were placed in the thalweg (i.e., lowest points along the length of the river bed) and shielded from direct sunlight. 
Study animals and housing conditions

129 Carmine shiner (total length: $64.1 \pm 0.8 \mathrm{mmm}$; body mass: $1.5 \pm 0.1 \mathrm{~g}$ (mean $\pm \mathrm{SE})$ ) were captured in the Birch River in Eastern Manitoba, Canada (N49.797117, W95.853357) using a beach seine (Carr et al., 2015) in August of 2011.

The fish were transferred to Fisheries and Oceans Canada's Freshwater Institute in Winnipeg, Manitoba where they were kept in 801 tanks in a temperature controlled room $(20 \pm$ $0.2{ }^{\circ} \mathrm{C}$ ) and fed daily with chironomid larvae ad libitum. Water temperatures at the collection sites on the Birch River ranged between $24-26{ }^{\circ} \mathrm{C}$. Temperature was reduced by $1{ }^{\circ} \mathrm{C}$ day ${ }^{-1}$ from the capture temperature to the holding temperature $\left(20 \pm 0.2{ }^{\circ} \mathrm{C}\right)$. Fish were acclimated to laboratory conditions for one month prior to experimentation. The photoperiod was $16 \mathrm{~h}$ light: 8 $\mathrm{h}$ dark during holding and throughout the experiment. Air stones ensured normoxic conditions (> $\left.95 \% \mathrm{O}_{2 \text { sat }}\right)$. Fish were fasted for $24 \mathrm{~h}$ prior to experimentation to ensure a post-absorptive state that maximized the energy available for performance. For all transfers between tanks, fish were guided into a container $(300 \mathrm{ml})$ and transported without air exposure (Poulsen et al., 2010).

Carmine shiner were collected from their natural environment under the provincial Scientific Collection Permit \#41-11 and the Species at Risk Permit \#CandA11-023. The endangered carmine shiner was studied to obtain valuable information on the species to provide science advice for the Recovery Potential Assessment and the Carmine Shiner Recovery Strategy. All procedures were reviewed and approved by the Animal Care Committee at the Freshwater Institute, Fisheries and Oceans Canada (Approval IDs: FWI-ACC-2010-012, FWIACC-2011-009, and FWI-ACC-2012-001) under the guidelines of the Canadian Council of 
Animal Care. All efforts were taken to circumvent animal suffering and undue stress, and there was no mortality during any of the tests.

\section{Experimental setup}

Shy-bold behavioural phenotypes were determined using established protocols (Killen et al., 2012). A circular arena tank (diameter: $50 \mathrm{~cm}$; water depth: $10 \mathrm{~cm}$ ) was video recorded from above using a camera (uEye RE 1640; Loligo Systems, Tjele, Denmark) and the recordings were transferred to a PC where the software LoliTrack (Loligo Systems) tracked individual fish. A crescent shaped cover $\left(80 \mathrm{~cm}^{2} ; 12 \mathrm{~cm}\right.$ long), made of black plastic ( $1 \mathrm{~mm}$ thick), attached to the tank wall was situated $1 \mathrm{~cm}$ above the water surface, and the arena bottom was darkened below the cover to create a hide with dim light. Preliminary trials revealed that carmine shiner preferred the hide over the area outside of the hide. Fish were not tracked directly after entering the hide, precluding any estimates of activity patterns when fish were situated inside the hide (i.e., under the black plastic cover). Fish tracking proceeded immediately when fish left the hide. Water temperature was adjusted to $20{ }^{\circ} \mathrm{C}$ (range: $19.9-20.1{ }^{\circ} \mathrm{C}$ ) using a temperature controlling instrument (TMP-REG; Loligo Systems). Oxygen saturation of the arena water remained > 95\% $\mathrm{O}_{2 \text { sat }}$ throughout the experiment.

An aerial predator attack was simulated by dropping a metal object $(58.1 \mathrm{~g})$ through an opaque vertical pipe (61 cm long; $5.8 \mathrm{~cm}$ in inner diameter) that ended $1 \mathrm{~cm}$ above the water surface. The pipe ensured that the fish could not see the approaching object until it was close to the water surface and entered the water. The metal object was stringed such that it broke the water surface but did not hit the bottom of the arena. The object was removed from the arena immediately after breaking the surface. The set-up minimized any confounding influence of 
individual variation in aerial detection distance and perception of objects hitting the bottom in addition to the water surface.

The arena and the camera were shrouded in an opaque plastic blind, while the upper pipe ending and the PC were outside of the plastic blind to allow the experimenter to carry out the study with minimal disturbance of the fish. Tracking data from the arena tank were used for behavioural phenotyping based on hourly estimates of four variables that are related to shy-bold behaviours: (1) total distance swum (equivalent to swimming speed) - this variable was included because shy-bold behavioural phenotyping is related to activity levels in fish according to previous studies (Wilson and Godin, 2009; Killen et al., 2012); (2) total time spent outside of the hide; (3) total time spent more than $3 \mathrm{~cm}$ from the tank wall; and (4) an index of exploration tendency based on crossings of a fictive line that divided the arena into two equal parts and situated furthest away from the hide.

\section{Measuring thermal preference}

Behavioural thermoregulation in a hetero-thermal environment was examined using established protocols (Petersen and Steffensen, 2003; Killen, 2014; Cooper et al., 2018). A shuttle box (Loligo Systems) was used to quantify temperature preference and avoidance in individual fish. The shuttle box consisted of two separate circular chambers (diameter: $50 \mathrm{~cm}$; water depth 10 $\mathrm{cm}$ ) connected via a corridor ( $8 \mathrm{~cm}$ long and $5 \mathrm{~cm}$ wide). Fish could pass freely between the two chambers using the corridor (Figure 1). The shuttle box was shielded from external disturbance and direct lighting by an opaque plastic blind.

Water temperature within each of the circular chambers was continuously monitored using inline temperature sensors; each connected to a computerized temperature controller and 
data acquisition system (DAQ-M instrument; Loligo Systems). The software ShuttleSoft (Loligo Systems, Tjele, Denmark) and heating and cooling baths were employed to control the water temperature in each chamber. This was accomplished using external buffer tanks connected to the shuttle box. A temperature difference of $2{ }^{\circ} \mathrm{C}$ between the two chambers was maintained throughout trials (Petersen and Steffensen, 2003), such that one of the chambers constantly was 2 ${ }^{\circ} \mathrm{C}$ colder than the other chamber.

In addition to temperature control, the buffer tanks were employed to control water oxygenation. Normoxic $\left(\geq 95 \% \mathrm{O}_{2 \text { sat }}\right)$ and hypoxic $\left(20 \% \mathrm{O}_{2 \text { sat }} ;\right.$ range: $\left.19.9-20.1 \% \mathrm{O}_{2 \text { sat }}\right)$ conditions were maintained by exposing water in the buffer tanks to streams of either air or nitrogen $\left(\mathrm{N}_{2}\right)$ bubbles. Air pumps were running continually during normoxic trials, while the supply of $\mathrm{N}_{2}$ for the hypoxic trials $\left(20 \% \mathrm{O}_{2 \mathrm{sat}}\right)$ was controlled by an oxygen controlling instrument (OXY-REG; Loligo Systems). Both chambers were adjusted to $20 \% \mathrm{O}_{2 \text { sat }}$ during the hypoxic trials.

A camera (uEye RE 1640; Loligo Systems, Tjele, Denmark) was mounted above the shuttle box and was used by the ShuttleSoft software to detect the position of the fish. The temperature controlling unit of the software was adjusted to be either in a static or dynamic mode. When in the static mode, there was a constant temperature in each chamber, but a $2{ }^{\circ} \mathrm{C}$ differential between them. Individual fish were transferred in the shuttle box in the early evening, allowing a $16 \mathrm{~h}$ acclimation period, and at $10 \mathrm{~h}$ in the morning, the shuttle box system was adjusted to the dynamic mode. The dynamic mode allows the temperature to change within the shuttle box depending on the position of the fish, while maintaining the $2{ }^{\circ} \mathrm{C}$ differential between the warm and cold chambers. Thus, when a fish moved into the warm chamber, the temperature increased in both sides of the shuttle box $\left(4{ }^{\circ} \mathrm{C} \mathrm{h}^{-1}\right)$, but the cold chamber was always $2{ }^{\circ} \mathrm{C}$ 
colder than the warm chamber (Petersen and Steffensen, 2003). Conversely, when a fish moved into the cold chamber, the temperature in both sides of the shuttle box began to decrease $\left(4{ }^{\circ} \mathrm{C} \mathrm{h}^{-}\right.$ ${ }^{1}$ ) (Petersen and Steffensen, 2003). Thus, by alternating between the warm and cold chambers of the shuttle box in response to changing temperatures, an individual could regulate the ambient temperature. This methodology to determine preferred temperatures was selected because it provides estimates that are consistent in individual fish (Killen, 2014) and not a consequence of random movements, as indicated by mock simulation trials (Nay et al., 2015).

\section{Experimental protocol}

For each of the 46 trials, an individual fish was transferred from the holding tank to the arena tank for behavioural phenotyping. Video recording and fish tracking started immediately after release and continued for $6 \mathrm{~h}$ in total. After $5 \mathrm{~h}$, the simulated aerial predator attack was conducted, and was followed by $1 \mathrm{~h}$ of continued fish tracking. Similar to Killen et al. (2012), the protocol provided $4 \mathrm{~h}$ of acclimation to the arena, $1 \mathrm{~h}$ of tracking before the predator attack and $1 \mathrm{~h}$ of tracking after the predator attack. Fish $(\mathrm{n}=46)$ were transferred directly to the shuttle box when the $6 \mathrm{~h}$ of fish tracking was complete. All fish were introduced to the centre of the shuttle box (i.e., in the corridor between the two compartments). Five fish did not move out of the centre of the shuttle box and are consequently not included in the analysis related to temperature.

For fish acclimation to the shuttle box $(16 \mathrm{~h})$, temperature was adjusted to $19{ }^{\circ} \mathrm{C}$ in the cold chamber and $21{ }^{\circ} \mathrm{C}$ in the warm chamber (static mode). Oxygen saturation was adjusted to either normoxic $\left(\geq 95 \% \mathrm{O}_{2 \text { sat }}\right)$ or hypoxic $\left(20 \% \mathrm{O}_{2 \text { sat }}\right)$ during the acclimation period and throughout the subsequent data collection. Oxygen saturation for each trial was chosen randomly. After the 
acclimation period, software settings were changed to the dynamic mode and the fish started thermoregulating by selecting the cold or warm chamber in response to the gradually changing environmental conditions. Over the next $10 \mathrm{~h}$, the fish was left undisturbed in the shuttle box and revealed its preferred temperature by avoiding lower and upper temperatures. An individual fish was tested under either normoxia or hypoxia. A total of 18 fish were tested under normoxic conditions and 23 fish under hypoxic conditions, respectively. The trial was terminated by measuring fish total length (to nearest $0.5 \mathrm{~mm}$ ) and body mass (to nearest $0.01 \mathrm{~g}$ ). After each trial, the arena tank and the shuttle box were cleaned and water was replaced.

\section{Data acquisition and statistical analyses}

Principal component analysis (PCA) was used to aggregate the four behavioural variables (i.e., (1) total distance swum; (2) total time spent outside of the hide; (3) total time spent more than 3 $\mathrm{cm}$ from the tank wall; and (4) an index of exploration tendency) that were measured during six separate time periods (each $1 \mathrm{~h}$ over the duration of the experiment) into one estimate of shybold behavioural phenotype for each fish (Wilson and Godin, 2009; Killen et al., 2012). Thus, for each hour spent in the arena tank, the PCA provided one estimate of the fish's behavioural phenotype. Negative and positive PCA values corresponded to shy and bold individuals, respectively; and the variable is hereafter referred to as 'risk score'. The risk scores immediately before and immediately after the simulated predator attack were then related to each other. Consistent with previous studies (Wilson and Godin, 2009; Killen et al., 2012), the PCA approach was applied to minimize any risk of spurious correlations resulting from multiple tests of behavioural traits (e.g., distance swum). The PCA approach eliminated the need for multiple tests corrections (i.e., the Bonferroni adjustments). Finally, the study was concerned with shy- 
bold behavioural phenotypes and not with related behavioural traits such as the distance swum. The intra-class correlation coefficient (Lessells and Boag, 1987; Wolak et al., 2012) also referred to as repeatability index (R) (Roche et al., 2016) was used to examine the consistency of the fish's behavioural phenotype across the $6 \mathrm{~h}$ of tracking. In particular the data were used to test the hypothesis that behavioural phenotype is consistently expressed before and after a predator attack. The analysis involved Spearman's rank correlation coefficient $(\rho)$ and hourly personality values (from the PCA) gathered immediately before and after the predator attack. Specifically, a significant positive correlation would indicate that an individual is relatively bold (or shy) both in a relaxed and disturbed state (i.e., before and after the simulated predator attack). All data collected in the arena tank involved normoxic water.

Thermal preference was estimated as the mean recorded temperature during the last $5 \mathrm{~h}$ of data collection (i.e., after $5 \mathrm{~h}$ of acclimation to changing temperatures in the shuttle box). Over the same time span, minimum and maximum thermal avoidance temperatures were estimated as the lower and upper recorded temperature (Schurmann and Steffensen, 1992). At the individual level, the thermal range was determined as the difference between the minimum and maximum avoidance temperatures. Least square linear regressions were used to examine correlations between shy-bold behavioural phenotypes (i.e., risk scores derived using the PCA, see supplementary data S1) and preferred temperatures, avoidance temperatures and thermal ranges. An analysis of covariance (ANCOVA) was conducted to test the effect of oxygen saturation and risk score on the preferred temperature, where hypoxia/normoxia was used as factor, preferred temperature as dependent variable, and the risk score (boldness) as covariate. Independently of shy-bold behavioural phenotype, the preferred and avoidance temperatures from normoxic and hypoxic trials were compared using a Welch Two Sample T-Test. Data analyses were carried out 
using the statistical software R (R Development Core Team, 2015). Results were considered significant at $P<0.05$. All values are reported as means \pm s.e.m. unless otherwise noted.

\section{RESULTS}

\section{Environmental variables measured in the field to support ecological relevance}

Over the one year sampling period, water temperatures in the Birch River, Manitoba, Canada varied between $0-30{ }^{\circ} \mathrm{C}$. Temperatures reached $20^{\circ} \mathrm{C}$ in late June and fluctuated between $20-$ $30{ }^{\circ} \mathrm{C}$ until late August, when temperatures started declining. Diel temperature changes peaked at $6-7{ }^{\circ} \mathrm{C}$. Dissolved oxygen concentrations fluctuated consistently over the diel period (Figure 2). Depending on river location and time, river oxygen saturation varied between $18.9-63.9 \% \mathrm{O}_{2 \text { sat }}$ (Figure 2).

\section{Shy-bold behavioural phenotype}

Shy-bold behavioural phenotypes varied widely between individual carmine shiner (Figure 3). Individuals with a higher risk score, i.e., higher PCA value, (1) swam a longer distance per hour; (2) spent longer time outside of the hide; (3) spent longer time more than $3 \mathrm{~cm}$ away from the tank wall; and (4) exhibited elevated exploration tendency (Table 1). The first and second principal component (PC1 and PC2) explained $72.9 \%$ and $21.1 \%$ of the variation (Figure 4). In all cases, the four behavioural traits correlated significantly with the risk score $(n=41 ; \rho>0.62$ -0.97 ; all $P<0.0001$ ), suggesting that the risk score aggregated the behavioural variation that existed between individuals.

Our analysis revealed that some fish were consistently bolder whereas others were consistently shyer. This was revealed by the significant intra-class correlation coefficient of the 
risk score $(n=46$; Repeatability Index $=0.62$, Confidence Interval $=0.5-0.74)$. These findings support our first hypothesis that shy-bold behavioural phenotypes can be consistent across time. Importantly, the risk score immediately before the simulated predator attack correlated to some extent with the risk score immediately after the simulated predator attack $(\rho=0.69 ; P<0.0001$; Figure 3).

The correlation of risk scores before and after the simulated predator attack was positive, indicating that individual fish exhibited similar shy-bold behavioural phenotype despite a predator attack. Thus, across situations, individual fish tended to maintain their behavioural risk score.

Correlations of shy-bold behavioural phenotypes with preferred temperature, avoidance temperatures, and thermal range

Analyses revealed no significant correlations between the shy-bold behavioural phenotypes and thermoregulatory behaviour (Figure 5). For example, risk scores recorded immediately before the simulated predator attack did not correlate with preferred temperatures in either normoxia or hypoxia (Figure $5, r^{2}<0.03 ; P>0.45$ ). Likewise, risk scores did not correlate with maximum or minimum avoidance temperatures $\left(r^{2}<0.18 ; P>0.09\right)$ or thermal range calculated as the maximum avoidance temperature minus the minimum avoidance temperature $\left(r^{2}<0.09 ; P>\right.$ 0.19). Collectively, the findings suggest that shy-bold behavioural phenotypes, assessed using risk scores, are poor predictors of thermoregulatory behaviours.

Temperature preference, avoidance temperatures, and thermal tolerance range: Effects of hypoxia 
Thermoregulatory behaviour was influenced by oxygen saturation. Oxygen saturation had a significant effect on the preferred temperature (ANCOVA, $F_{1,45}=13.57 ; P<0.001$ ) but shybold behavioural phenotypes, assessed using risk scores had no effect on the preferred temperature (ANCOVA, $F_{1,45}=0.04 ; P=0.85$ ). In hypoxia, the preferred temperature was significantly $(t=-4.01 ; d f=34.92 ; P<0.001)$ lower than in normoxia (Figure 6). Likewise, the maximum avoidance temperature in hypoxia was significantly $(t=-3.93 ; d f=31.75 ; P<0.001)$ lower than in normoxia (Figure 6) indicating that fish with reduced aerobic performance selected lower temperatures. However, this pattern was not the case in terms of the minimum avoidance temperature (Figure 6). While the minimum avoidance temperature was lower in hypoxia compared to normoxia, the difference was not statistically significant $(t=-1.74 ; d f=35.72 ; P>$ $0.09)$.

\section{DISCUSSION}

Using the endangered carmine shiner, this study provides evidence of consistent behavioural phenotypes, forming individual phenotypes along the shy-bold continuum. We observed interindividual variations in behavioural phenotypes with shyer individuals swimming shorter distances, spending longer time inside the hide and near the walls as well as exhibiting reduced exploratory tendency. As predicted, shy-bold behavioural phenotypes were consistent across situations. Importantly, behavioural phenotypes were consistent before and after a predator attack. The persistence of the shy-bold behavioural phenotypes after a predator attack indicates that individuals maintain their shy-bold behavioural phenotype, independently of changes in the environment. Correspondingly, selection may act on behavioural phenotypes and favour phenotypes that are adapted behaviourally to co-exist with abundant predators (Lapiedra et al., 
2018; Travis and Reznick, 2018). Carmine shiner are thought to occur in loosely associated small groups, consequently having tested the behaviour and temperature preferences individually might have affected our results as the presence of a conspecific may have altered their behaviour and potentially the thermal preference between bold and shy individuals.

In fish, bolder individuals often experience elevated mortality (Hulthén et al., 2017), however, bolder individuals might be able to alleviate the consequences of their behavioural phenotype using greater behavioural plasticity after a predator attack. Compared to shyer conspecifics, bolder individuals could exhibit wider behavioural plasticity and a safer response to predation by becoming excessively quiescent and/or sheltering after a predator attack (Andersen et al., 2015). This hypothesis would suggest no correlation or even a negative correlation between risk scores before and after a predator attack. In contrast, our data revealed a positive correlation between risk scores before and after a simulated predator attack, suggesting that bolder individuals maintained their shy-bold behavioural phenotype, even in the presence of a simulated predator. Consequently, our findings indicate that animals exhibit limited flexibility in their behavioural repertoire across different situations. Our data adds to the mechanistic basis of the elevated predation cost experienced by bolder phenotypes in the wild (Hulthén et al., 2017) and suggest that behavioural diversity is maintained by parallel selection on other co-varying traits (e.g., physiological traits). Further study is warranted to clarify why bold individuals apparently do not adjust their boldness, even in the presence of immediate predation risk.

In comparisons between individuals, various traits may co-vary within individuals (Biro and Stamps, 2010; Killen et al., 2012). This is the basis of the pace-of-life syndrome (POLS) where a range of behavioural phenotypes are predicted to co-vary with other traits, including life history and physiology (Réale et al., 2010). Studies have revealed that shy-bold behavioural 
phenotypes may co-vary with body length (Polverino et al., 2016) and metabolic rates (Killen et al., 2012; Binder et al., 2016), providing support for the POLS hypothesis. Temperature is the most influential environmental variable and determines development rates in ectothermic animals. Specifically, energy metabolism typically increases exponentially with water temperature (Rosewarne et al., 2016), highlighting the importance of thermoregulatory behaviours in ectothermic animals. Although thermoregulatory behaviour was not considered by Réale et al. (2010) when they described the POLS hypothesis, we examined relationships between behavioural phenotypes and thermoregulatory behaviours. Indeed, recent studies have revealed the large impacts of variation in thermoregulatory behaviours (Killen, 2014; Cooper et al., 2018). In aquatic environments, temperature may vary both horizontally and vertically, but thermal preference by different behavioural phenotypes has received limited attention (VillegasRíos et al., 2018). In the present study, we hypothesized that bolder individuals show a preference for higher temperatures, relative to shy counterparts. As ambient temperature deviates from the thermal optimum in either direction (i.e., increasing or decreasing water temperature), foraging and growth rates are expected to decline. This behaviour would elevate energy metabolism and food requirements in the bolder fish, consistent with the POLS hypothesis (Réale et al., 2010). However, data revealed no support for the hypothesis, suggesting that traits different from shy-bold behaviour drive intraspecific variation in thermoregulatory behaviour.

In contrast, oxygen saturation seems to influence the thermoregulatory behaviours. Specifically, for ectothermic animals, preferred water temperature, maximum avoidance temperature, and thermal tolerance range were suppressed significantly in hypoxia. Consistent with the OCLTT hypothesis (Pörtner, 2010; Pörtner et al., 2017), these findings indicate that fish selected lower temperatures and tolerated a narrower temperature amplitude in response to 
402

403

404

405

406

407

408

409

410

411

412

413

414

415

416

417

418

419

420

reduced aerobic performance. At a global scale, hypoxia is an increasing problem in many aquatic areas (Schmidtko et al., 2017; Breitburg et al., 2018). While oxygen thresholds for physiological performances (Rogers et al., 2016) and hypoxia avoidance behaviours (Schurmann et al., 1998; Chabot and Claireaux, 2008; Poulsen et al., 2011) have been examined, thermoregulatory behaviours in hypoxia have received limited attention. Consistent with previous studies (Schurmann and Steffensen, 1992), our data suggest that thermoregulatory behaviours are susceptible to changes in oxygen saturation. Specifically, hypoxia reduced preferred and maximum avoidance temperatures as well as the thermal tolerance range. Tank experiments have revealed that fish growth is also suppressed by hypoxia. For example, Chabot and Dutil (1999) reported reduced growth in Atlantic cod (Gadus morhua) in moderate levels of hypoxia at $10{ }^{\circ} \mathrm{C}$. Using direct comparisons between normoxia and hypoxia at a common temperature, such studies reveal the distinct effects of hypoxia on growth, but the studies rarely account for the concomitant lower preferred temperatures in hypoxia that fish may exhibit in the field. Direct hypoxia effects combined with a preference for lower temperatures likely modifies the effects of hypoxia on growth. Therefore, studies examining growth rates at different oxygen levels should account for concomitant variation in the preferred temperature presumably displayed in the field. In the present study, field sampling revealed that carmine shiner is exposed to hypoxia levels similar to the levels tested in the lab, at least during parts of diel cycle. These findings suggest that carmine shiner growth may be constrained by hypoxia in the Birch River, partly because aerobic performance is suppressed, partly because the fish likely prefer temperatures that are suboptimal for growth compared to normoxic conditions.

Although the OCLTT hypothesis is attractive, temperature and hypoxia effects on fish are complex and various examples exist that do not comply with the OCLTT hypothesis (Clark et 
al., 2013, Jutfelt et al., 2018). In a heterothermal environment, fish control their temperature by avoiding unfavourable temperatures and seeking more favourable temperatures as tested in our laboratory experiment, in which fish were allowed to choose their temperature by shuttling back and forth in the experimental setup. The present study illustrates that carmine shiner can thermoregulate behaviourally and that their thermoregulatory behaviour is influenced by oxygen saturation. In normoxia, fish preferred higher temperatures $\left(25.2{ }^{\circ} \mathrm{C}\right)$ than in hypoxia $\left(22.6{ }^{\circ} \mathrm{C}\right)$. Similarly, the maximum avoidance temperature in normoxia $\left(28.6^{\circ} \mathrm{C}\right)$ was higher than in hypoxia $\left(26.1^{\circ} \mathrm{C}\right)$ suggesting that fish with reduced aerobic performance selected lower water temperatures. The wide range of minimum and maximum temperatures, ranging from $18.4-$ $28.6{ }^{\circ} \mathrm{C}$ in normoxia and $17.6-26.1{ }^{\circ} \mathrm{C}$ in hypoxia, suggests that carmine shiner is a warm water species that tolerates a range of water temperatures (i.e., eurytherm species). The temperature and oxygen saturation ranges correspond largely to the summer temperatures and oxygen saturations that were observed in the natural habitat of carmine shiner. We have transferred fish in temperature ranging from $22-25{ }^{\circ} \mathrm{C}$ back to our laboratory facility before encountering mortalities. However, temperatures in the field reached $30{ }^{\circ} \mathrm{C}$ during the summer, which exceeded both the maximum avoidance temperature $\left(28.6^{\circ} \mathrm{C}\right)$ and the preferred temperatures $\left(25.2{ }^{\circ} \mathrm{C}\right.$ and $22.6^{\circ} \mathrm{C}$ in normoxia and hypoxia, respectively), indicating that carmine shiners are exposed to suboptimal temperatures in the Birch River. With warming summers in Canada as a consequence of climate change (Schindler et al., 1996), this suboptimal thermal exposure could be exacerbated.

Predictions of future climate change suggest large and deleterious effects on freshwater fish species with narrow dispersal abilities due to limited hydrological connectivity (Dudgeon, 2010). In turn, this creates the potential for population isolation in thermally unsuitable habitats, 
leading to physiological stress, species declines or possible extirpation. Carmine shiner currently occupy habitats spanning a wide range of climatic conditions. July mean temperature and temperature seasonality explain carmine shiner's current distribution (Pandit et al., 2017), indicating that temperature plays a dominant role in determining the spatial extent of occupancy. Consequently, our results are timely to understand the thermal preference of carmine shiner, which will help to guide effective management and conservation actions for this species. The field measurements and the experiments were conducted under summer conditions, consequently we can only speculate if carmine shiner experience hypoxia events during the winter. Due to the fact that there are several higher gradient sections in the Birch River that stay open over the winter albeit the general harsh winter condition, the water in the Birch River may actually be very well oxygenated and consequently hypoxia might be less of an issue for carmine shiner during winter months.

Water temperature and dissolved oxygen concentrations are linked in natural environment and organisms may have to trade-off between their thermal and dissolved oxygen requirements according to the thermal niche-dissolved oxygen hypothesis (Coutant, 1985). In our experimental setup, we purposely decoupled temperature from the dissolved oxygen concentration. One interpretation of why carmine shiner prefer colder water in hypoxic conditions may be a thermoregulatory compensatory mechanism. Specifically, for ectothermic fish, warmer water increases metabolic demand, requiring higher levels of oxygen intake. However, if the partial pressure of oxygen that determines the oxygen availability for fish is not available, then the required oxygen demand cannot be met; which may result in reduced growth and fitness. To avoid this scenario, individuals might seek out cooler water temperatures in their natural environment, where the combination of lower metabolic demand and higher dissolved oxygen 
concentrations is more likely to meet the metabolic demand. However, this mechanism could be further influenced by food availability due to temperature effects on food conversion efficiency. In conclusion, our study provides support for behavioural consistency where animals exhibit limited flexibility in their behavioural repertoire across different situations, precluding reduced boldness after a predator attack and possibly constraining evolutionary responses. We further hypothesized that bolder individuals would select higher temperatures to increase development rates consistent with the POLS hypothesis. The data did not, however, provide support for the hypothesis. Finally, our results suggest that fish select lower temperature in hypoxia consistent with the OCLTT hypothesis. Further research will be required to understand the impact of bold-shy behavioural types play in an ecosystem context.

\section{Acknowledgments}

This research was supported by funding from the Species at Risk program of Fisheries and Oceans Canada to E.C. Enders. Doug Watkinson and Elliot MacDonald assisted with fish collection. Thanks also to Jenni Konken and Michelle Saboraki for assistance with fish maintenance. We would like to thank David Callaghan and Tyana Rudolfsen for help with the video and data analysis. We would also like to thank Dominique Roche and four anonymous reviewers for the constructive review of an earlier version of the manuscript. The procedures described in this paper comply with animal care guidelines approved within Canada.

\section{References}

Andersen, B. S., Jørgensen, C., Eliassen, S., Giske, J. 2015. The proximate architecture for decision-making in fish. Fish Fish. 17(3), 680-695. https://doi.org/10.1111/faf.12139 
Autumn, K., De Nardo, D.F. 1995. Behavioral thermoregulation increases growth rate in a nocturnal lizard. J. Herpetol. 29(2), 157-162. https://doi.org/10.2307/1564552

Behrens, J.W., Svendsen, J.C., Neuenfeldt, S., Andersen, N.G., van Deurs, M. 2018. Individual variation in aerobic scope affects modelled vertical foraging migration in Atlantic cod Gadus morhua, but only in moderate hypoxia. Mar. Ecol. Progr. Ser., 599, 201-208.

Bell, A.M. 2007. Future directions in behavioural syndromes research. Proc. Roy. Soc. B: Biol. Sci. 274(1611), 755-761. https://doi.org/10.1098/rspb.2006.0199

Bell, A.M., Hankison, S.J., Laskowski, K.L. 2009. The repeatability of behaviour: a metaanalysis. Anim. Behav. 77(4), 771-783. https://doi.org/10.1016/j.anbehav.2008.12.022

Binder, T.R., Wilson, A.D.M., Wilson, S.M., Suski, C.D., Godin, J.G.J., Cooke, S.J. 2016. Is there a pace-of-life syndrome linking boldness and metabolic capacity for locomotion in bluegill sunfish? Anim. Behav. 121, 175-183. https://doi.org/10.1016/j.anbehav.2016.09.006

Biro, P.A., Adriaenssens, B., Sampson, P. 2014. Individual and sex-specific differences in intrinsic growth rate covary with consistent individual differences in behaviour. J. Anim. Ecol. 83(5), 1186-1195. https://doi.org/10.1111/1365-2656.12210

Biro, P.A., Stamps, J.A. 2010. Do consistent individual differences in metabolic rate promote consistent individual differences in behavior? Trends Ecol. Evol. 25(11), 653-659. https://doi.org/10.1016/j.tree.2010.08.003

Boel, M., Aarestrup, K., Baktoft, H., Larsen, T., Søndergaard Madsen, S., Malte, H., Skov, S., Svendsen, J.C., Koed, A. 2014. The physiological basis of the migration continuum in brown trout (Salmo trutta). Physiol. Biochem. Zool. 87(2), 334-345. https://doi.org/10.1086/674869 
Breau, C., Cunjak, R.A., Peake, S.J. 2011. Behaviour during elevated water temperatures: Can physiology explain movement of juvenile Atlantic salmon to cool water? J. Anim. Ecol. 80(4), 844-853. https://doi.org/10.1111/j.1365-2656.2011.01828.x

Breitburg, D., Levin, L.A., Oschlies, A., Grégoire, M., Chavez, F.P., Conley, D.J., Garçon, V., Gilbert, D., Gutiérrez, D., Isensee, K., Jacinto, G.S., Limburg, K.E., Montes, I., Naqvi, S.W.A., Pitcher, G.C., Rabalais, N.N., Roman, M.R., Rose, K.A., Seibel, B.A., Telszewski, M., Yasuhara, M., Zhang, J. 2018. Declining oxygen in the global ocean and coastal waters. Science 359(6371), eaam7240. https://doi.org/10.1126/science.aam7240

Brown, G.E., Ferrari, M.C.O., Malka, P.H., Fregeau, L., Kayello, L., Chivers, D.P. 2013. Retention of acquired predator recognition among shy versus bold juvenile rainbow trout. Behav. Ecol. Sociobiol. 67(1), 43-51. https://doi.org/10.1007/s00265-012-1422-4

Carr, M., Watkinson, D.A., Svendsen, J.C., Enders, E.C., Long, J.M., Lindenschmidt, K.-E. 2015. Geospatial modeling of the Birch River: Distribution of carmine shiner (Notropis percobromus) in Geomorphic Response Units (GRU). Internat. Rev. Hydrobiol. 100(56), 129-140. https://doi.org/10.1002/iroh.201501789

Carter, A.J., Feeney, W.E., Marshall, H.H., Cowlishaw, G., Heinsohn. R. 2013. Animal personality: What are behavioural ecologists measuring? Biol. Rev. 88: 465-475.

Carter, A.J., Goldizen, A.W., Tromp, S.A. 2010. Agamas exhibit behavioral syndromes: Bolder males bask and feed more but may suffer higher predation. Behav. Ecol. 21(3), 655-661. https://doi.org/10.1093/beheco/arq036

Chabot, D., Claireaux, G. 2008. Environmental hypoxia as a metabolic constraint on fish: the case of Atlantic cod, Gadus morhua. Mar. Poll. Bull. 57, 287-294. https://doi.org/10.1016/j.marpolbul.2008.04.001 
Chabot, D., Dutil, J.-D. 1999. Reduced growth of Atlantic cod in non-lethal hypoxic. J. Fish Biol. 55, 472-491.

Clark, T.D., Sandblom, E., Jutfelt, F. 2013. Aerobic scope measurements of fishes in an era of climate change: Respirometry, relevance and recommendations. J. exp. Biol. 216: 27712782. doi: $10.1242 /$ jeb. 084251

Conrad, J.L., Weinersmith, K.L., Brodin, T., Saltz, J.B., Sih, A. 2011. Behavioural syndromes in fishes: A review with implications for ecology and fisheries management. J. Fish Biol. 78(2), 395-435. https://doi.org/10.1111/j.1095-8649.2010.02874.x

Cooper, B., Adriaenssens, B., Killen, S.S. (2018). Individual variation in the compromise between social group membership and exposure to preferred temperatures. Proc. Roy. Soc. B: Biol. Sci. 285(1880), 1-9. https://doi.org/10.1098/rspb.2018.0884

Coutant, C.C. 1985. Striped bass, temperature, and dissolved oxygen: A speculative hypothesis for environmental risk. Trans. Am. Fish. Soc. 114, 31-61, doi:10.1577/15488659(1985)114<31:SBTADO>2.0.CO;2

Dochtermann, N.A., Dingemanse, N.J. 2013. Behavioral syndromes as evolutionary constraints, Behav. Ecol. 24(4), 806-811. https://doi.org/10.1093/beheco/art002

Dudgeon, D. 2010. Treats to freshwater biodiversity in a changing world. B. Freedman (Ed.), Global Environmental Change, Springer Science and Business Media, Dordrecht, The Netherlands, pp. 243-253.

Elliott, J.M., Hurley, M.A. 2000. Daily energy intake and growth of piscivorous brown trout, Salmo trutta. Freshwat. Biol. 44, 237-245.

Fisheries and Oceans Canada 2018. Action Plan for the carmine shiner (Notropis percobromus) in Canada. Species at Risk Act Action Plan Series. Fisheries and Oceans Canada, Ottawa. 
iv + 14 pp. https://www.registrelep-sararegistry.gc.ca/virtual_sara/files/plans/ApCarmineShiner-v00-2018Aug-Eng.pdf

Frost, A.J., Winrow-Giffen, A., Ashley, P.J., Sneddon, L.U. 2007. Plasticity in animal personality traits: Does prior experience alter the degree of boldness? Proc. Roy. Soc. B: Biol. Sci. 274(1608), 333-339. https://doi.org/10.1098/rspb.2006.3751

Guevara-Fletcher, C., Alvarez, P., Sanchez, J., Iglesias, J. 2016. Effect of temperature on the development and mortality of European hake (Merluccius merluccius L.) eggs from southern stock under laboratory conditions. J. Exp. Mar. Biol. Ecol. 476, 50-57. https://doi.org/10.1016/j.jembe.2015.11.018

Hulthén, K., Chapman, B.B., Nilsson, P.A., Hansson, L.A., Skov, C., Brodersen, J., Vinterstare J., Brönmark, C. 2017. A predation cost to bold fish in the wild. Sci. Rep. 7(1), 1-5. https://doi.org/10.1038/s41598-017-01270-w

Joblin, M. 1981. Temperature tolerance and the final preferendum-rapid methods for the assessment of optimum growth temperatures. J. Fish Biol. 19, 439-455. https://doi.org/10.1111/j.1095-8649.1981.tb05847.x

Jutfelt, F., Norin, T., Ern R., Overgaard, J., Wang, T., McKenzie, D.J., Lefevre, S., Nilsson, G.E., Metcalfe, N.B., Hickey, A.J.R., Brijs, J., Speers-Roesch, B., Roche, D.G., Gamperl, A.K., Raby, G.D., Morgan, R., Esbaugh, A.J., Gräns, A., Axelsson, M., Ekström, A., Sandblom, E., Binning, S.A., Hicks, J.W., Seebacher, F., Jørgensen, C., Killen, S.S., Schulte, P.M., Clark, T.D. 2018. Oxygen- and capacity-limited thermal tolerance: blurring ecology and physiology. J. exp. Biol. 221, jeb169615. doi:10.1242/jeb.169615

Kie, J. 1999. Optimal foraging and risk of predation: Effects on behavior and social structure in ungulates. J. Mammal. 80(4), 1114-1129. doi:10.2307/1383163 
Killen, S.S., Marras, S., Ryan, M., Domenici, P., McKenzie, D.J. 2012. A relationship between metabolic rate and risk-taking behaviour is revealed during hypoxia in juvenile European sea bass. Funct. Ecol. 26(1), 134-143. https://doi.org/10.1111/j.1365-2435.2011.01920.x

Killen, S.S. 2014. Growth trajectory influences temperature preference in fish through an effect on metabolic rate. J. Anim. Ecol. 83, 1513-1522. https://doi.org/10.1111/13652656.12244

Killen, S.S., Marras, S., Metcalfe, N.B., McKenzie, D.J., Domenici, P. 2013. Environmental stressors alter relationships between physiology and behaviour. Trends Ecol. Evol. 28(11), 651-658. https://doi.org/10.1016/j.tree.2013.05.005

Killen, S.S., Marras, S., Steffensen, J.F., McKenzie, D.J. 2012. Aerobic capacity influences the spatial position of individuals within fish schools. Proc. Roy. Soc. B: Biol. Sci. 279(1727), 357-364. https://doi.org/10.1098/rspb.2011.1006

Lapiedra, O., Schoener, T.W., Leal, M., Losos, J. B., Kolbe, J.J. 2018. Predator-driven natural selection on risk-taking behavior in anole lizards. Science 360(6392), 1017-1020. https://doi.org/10.1126/science.aap9289

Lessells, C.M., Boag, P.T. 1987. Unrepeatable repeatabilities: A common mistake. Auk 104, 116-121. https://doi.org/10.2307/4087240

Lillywhite, H.B., Licht, P., Chelgren, P. 1973. The role of behavioral thermoregulation in the growth energetics of the toad, Bufo boreas. Ecology 54(2), 375-383. https://doi.org/10.2307/1934345

Massen, J.J.M., Antonides, A., Arnold, A.M.K., Bionda, T., Koski, S.E. 2013. A behavioral view on chimpanzee personality: Exploration tendency, persistence, boldness, and toolorientation measured with group experiments. Am. J. Primat. 75(9), 947-958. 
609

610

611

612

613

614

615

616

617

618

619

620

621

622

623

624

625

626

627

628

629

630

631

https://doi.org/10.1002/ajp.22159

Mazué, G.P.F., Dechaume-Moncharmont, F.X., Godin, J.G.J. 2015. Boldness-exploration behavioral syndrome: Interfamily variability and repeatability of personality traits in the young of the convict cichlid (Amatitlania siquia). Behav. Ecol. 26(3), 900-908. https://doi.org/10.1093/beheco/arv030

Nay, T.J., Johansen, J.L., Habary, A., Steffensen, J.F., Rummer, J.L. 2015. Behavioural thermoregulation in a temperature-sensitive coral reef fish, the five-lined cardinalfish (Cheilodipterus quinquelineatus). Coral Reefs 34(4), 1261-1265. https://doi.org/10.1007/s00338-015-1353-4

Pandit, S.N., Maitland, B.M. Pandit, L.K., Poesch, M.S. Enders E.C. 2017. Climate change risks, extinction debt, and conservation implications for an endangered freshwater fish: carmine shiner (Notropis percobromus). Sci. Total Environ. 598, 1-11.

Pellegrini, A.F.A., Wisenden, B.D., Sorensen, P.W. 2010. Bold minnows consistently approach danger in the field and lab in response to either chemical or visual indicators of predation risk. Behav. Ecol. Sociobiol. 64(3), 381-387. https://doi.org/10.1007/s00265-009-0854-y

Petersen, M.F., Steffensen, J.F. 2003. Preferred temperature of juvenile Atlantic cod Gadus morhua with different haemoglobin genotypes at normoxia and moderate hypoxia. J. exp. Biol. 206(2), 359-364. https://doi.org/10.1242/jeb.00111

Pink, M., Abrahams, M.V., Krkošek, M. 2016. Temperature and its impact on predation risk within aquatic ecosystems. Can. J. Fish. Aquat. Sci. 73(6), 869-876. https://doi.org/10.1139/cjfas-2015-0302

Polverino, G., Bierbach, D., Killen, S.S., Uusi-Heikkiliä, S., Arlinghaus, R. 2016. Body length rather than routine metabolic rate and body condition correlates with activity and risk- 
632

633

634

635

636

637

638

639

640

641

642

643

644

645

646

647

648

649

650

651

652

653

654

taking in juvenile zebrafish Danio rerio. J. Fish Biol. 89(5), 2251-2267. https://doi.org/10.1111/jfb.13100

Pörtner, H.-O. 2010. Oxygen- and capacity-limitation of thermal tolerance: A matrix for integrating climate-related stressor effects in marine ecosystems. J. exp. Biol. 213, 881893. https://doi.org/10.1242/jeb.037523

Pörtner, H.-O., Bock, C., Mark, F.C. 2017. Oxygen- and capacity-limited thermal tolerance: bridging ecology and physiology. J. exp. Biol. 220(15), 2685-2696. https://doi.org/10.1242/jeb.134585

Pörtner, H.-O, Knust R. 2007. Climate change affects marine fishes through the oxygen limitation of thermal tolerance. Science 315(5808), 95-97. doi:10.1126/science.1135471

Pörtner, H.-O., Peck, M.A. 2010. Climate change effects on fishes and fisheries: Towards a cause-and-effect understanding. J. Fish Biol. 77(8), 1745-1779. https://doi.org/10.1111/j.1095-8649.2010.02783.x

Poulsen, S.B., Jensen, L.F., Nielsen, K.S., Malte, H., Aarestrup, K., Svendsen, J.C. 2011. Behaviour of rainbow trout Oncorhynchus mykiss presented with a choice of normoxia and stepwise progressive hypoxia. J. Fish Biol. 79(4), 969-979. https://doi.org/10.1111/j.1095-8649.2011.03069.x

Poulsen, S.B., Svendsen, J.C., Jensen, L.F., Schulz, C., Jäger-Kleinicke, T., Schwarten, H. 2010. Effects of food deprivation on refuge use and dispersal in juvenile North Sea houting Coregonus oxyrinchus under experimental conditions. J. Fish Biol. 77(7), 17021708. https://doi.org/10.1111/j.1095-8649.2010.02772.x

R Development Core Team (2015). R: A language and environment for statistical computing. R Foundation for Statistical Computing, Vienna, Austria. http://www.R-project.org/ 
655

656

657

658

659

660

661

662

663

664

665

666

667

668

669

670

671

672

673

674

675

676

677

Réale, D., Garant, D., Humphries, M. M., Bergeron, P., Careau, V., Montiglio, P.-O. 2010. Personality and the emergence of the pace-of-life syndrome concept at the population level. Phil. Trans. Roy. Soc. B: Biol. Sci. 365(1560), 4051-4063. https://doi.org/10.1098/rstb.2010.0208

Roche, D.G., Careau, V., Binning, S.A. 2016. Demystifying animal 'personality'(or not): Why individual variation matters to experimental biologists. J. exp. Biol. 219, 3832-3843. doi:10.1242/jeb.146712

Rogers, N.J., Urbina, M.A., Reardon, E.E., Mckenzie, D., Wilson, R.W. 2016. A new analysis of hypoxia tolerance in fishes using a database of critical oxygen level $\left(\mathrm{P}_{\text {crit }}\right)$. Cons. Physiol. 4(1), cow012. https://doi.org/10.1093/conphys/cow012.

Rosewarne, P.J., Wilson, J.M., Svendsen, J.C. 2016. Measuring maximum and standard metabolic rates using intermittent flow respirometry: a student laboratory investigation of aerobic metabolic scope and environmental hypoxia in aquatic breathers. J. Fish Biol. 88, 265-283. https://doi.org/10.1111/jfb.12795

Schindler, D.W., Bayley, S.E., Parker, B.R., Beaty, K.G., Cruikshank, D.R., Fee, E.J., Stainton, M.P. 1996. The effects of climatic warming on the properties of boreal lakes and streams at the Experimental Lakes Area, northwestern Ontario. Limnol. Oceanograph. 41, 10041017.

Schmidtko, S., Stramma, L., Visbeck, M. 2017. Decline in global oceanic oxygen content during the past five decades. Nature 542(7641), 335-339.

Schurmann, H., Claireaux, G., Chartois, H. 1998. Changes in vertical distribution of sea bass (Dicentrarchus labrax L.) during a hypoxic episode. Hydrobiologia 371/372, 207-213. https://doi.org/10.1023/A 
678

679

680

681

682

683

684

685

686

687

688

689

690

691

692

693

694

695

696

697

698

699

700

Schurmann, H., Steffensen, J.F. 1992. Lethal oxygen levels at different temperatures and the preferred temperature during hypoxia of the Atlantic cod, Gadus morhua L. J. Fish Biol. 41, 927-934. https://doi.org/10.1111/j.1095-8649.1992.tb02720.x

Short, K.H., Petren, K. 2008. Boldness underlies foraging success of invasive Lepidodactylus lugubris geckos in the human landscape. Anim. Behav. 76(2), 429-437. https://doi.org/10.1016/j.anbehav.2008.04.008

Sommer-Trembo, C., Petry, A.C., Gomes Silva, G., Vurusic, S. M., Gismann, J., Baier, J., Krause, S., Iorio, J.A.C., Riesch, R., Plath, M. 2017. Predation risk and abiotic habitat parameters affect personality traits in extremophile populations of a neotropical fish (Poecilia vivipara). Ecol. Evol. 7(16), 6570-6581. https://doi.org/10.1002/ece3.3165

Svendsen, J.C., Genz, J., Anderson, W.G., Stol, J.A., Watkinson, D.A., Enders, E.C. 2014. Evidence of circadian rhythm, oxygen regulation capacity, metabolic repeatability and positive correlations between forced and spontaneous maximal metabolic rates in lake sturgeon Acipenser fulvescens. PLoS ONE 9(4), e94693.

https://doi.org/10.1371/journal.pone.0094693

Travis, J., Reznick, D.N. 2018. Natural selection: how selection on behavior interacts with selection on morphology. Current Biol. 28(16), R882-R884. https://doi.org/10.1016/j.cub.2018.07.006

Villegas-Ríos, D., Réale, D., Freitas, C., Moland, E., Olsen, E.M. 2018. Personalities influence spatial responses to environmental fluctuations in wild fish. J. Anim. Ecol. 87(5), 13091319. https://doi.org/10.1111/1365-2656.12872

Ward, A.J.W., Thomas, P., Hart, P.J.B., Krause, J. 2004. Correlates of boldness in three-spined sticklebacks (Gasterosteus aculeatus). Behav. Ecol. Sociobiol. 55(6), 561-568. 
https://doi.org/10.1007/s00265-003-0751-8

Watanabe, N.M., Stahlman, W.D., Blaisdell, A.P., Garlick, D., Fast, C.D., Blumstein, D.T. 2012. Quantifying personality in the terrestrial hermit crab: different measures, different inferences. Behav. Proc. 91(2), 133-140. https://doi.org/10.1016/j.beproc.2012.06.007

Wilson, A.D.M., Godin, J.G.J. 2009. Boldness and behavioral syndromes in the bluegill sunfish, Lepomis macrochirus. Behav. Ecol. 20(2), 231-237. https://doi.org/10.1093/beheco/arp018

Wolak, M.E., Fairbairn, D.J., Paulsen, Y.R. 2012. Guidelines for estimating repeatability. Meth. Ecol. Evol. 3, 129-137.

Wong, B.B.M., Candolin, U. 2015. Behavioral responses to changing environments, Behav. Ecol. 26(3), 665-673. https://doi.org/10.1093/beheco/aru183 
Table captions:

714 Table 1. Factor loadings for the four behavioural variables tested on the first principal

715 component (PC1) and second principal component (PC2) of the principal component analysis.

\begin{tabular}{lcc}
\hline Behavioural phenotyping variable & PC1 & PC2 \\
\hline Total distance swum & 0.534 & 0.309 \\
Total time spent outside of the hide & 0.553 & -0.258 \\
Total time spent $>3 \mathrm{~cm}$ from the tank wall & 0.442 & -0.685 \\
Index of exploration tendency & 0.462 & 0.607
\end{tabular}




\section{Figure captions:}

Figure 1. Experimental setup of the shuttle box trials. Hypoxic conditions (20\% air saturation) were achieved by bubbling nitrogen in both buffer tanks and monitored by galvanic oxygen sensors inside the buffer tanks and an instrument controlling the supply of nitrogen (Oxy-Reg, Loligo Systems, Tjele, Denmark).

Figure 2. Average and confidence intervals of dissolved oxygen content (\% oxygen saturation $\left(\mathrm{O}_{2 \text { sat }}\right)$ ) over $24 \mathrm{~h}$ in three different locations in the Birch River, Manitoba, Canada: river location N49.79770 W95.85489 by $\bullet$, N49.67943 W95.78884 indicated by $\boldsymbol{\square}$, and N49.62990 W95.70113 by $\boldsymbol{\Lambda}$, showing a large variation in $\mathrm{O}_{2 \text { sat }}$ between sites. Average dissolved oxygen saturation varied between $18.9-63.9 \% \mathrm{O}_{2 \text { sat }}$ and revealed a clear diel pattern. The dissolved oxygen saturation reached the upper peak in the afternoon $(15-16 \mathrm{~h})$ and the lower peak in the morning $(7-8 \mathrm{~h})$. The diel amplitude varied between $9.6-18.7 \% \mathrm{O}_{2 \mathrm{sat}}$.

Figure 3. Risk score derived using PCA before (x-axis) and after (y-axis) a simulated predator attack. The risk score is an index of boldness with higher values indicating bolder individuals (n =46). The two data sets are positively correlated indicating that a bold fish generally remains bold after a predator attack $(\mathrm{n}=46 ; \rho=0.69 ; P<0.0001)$.

Figure 4. Results from the principal component analysis used to aggregate the four variables into one estimate of shy-bold behavioural phenotype, i.e., (1) total distance swum, (2) total time spent outside of the hide; (3) total time spent more than $3 \mathrm{~cm}$ from the tank wall; and (4) an index of exploration tendency per fish. 
741 Figure 5. Relationship between bold-shy behaviour estimated as risk score before a simulated 742 predator attack and the temperature preference of a given fish.

743

744 Figure 6. Minimum avoidance, preferred and maximum avoidance temperature in normoxia $(\mathrm{n}=$ 745 18) and hypoxia $(\mathrm{n}=23)$. Preferred and maximum temperature are significantly $(\mathrm{p}<0.001)$ 746 lower in hypoxia. In contrast, minimum avoidance temperatures in normoxia and hypoxia are not 747 statistically different $(\mathrm{p}>0.44)$. 
Figures:

$750 \quad$ Fig. 1

751

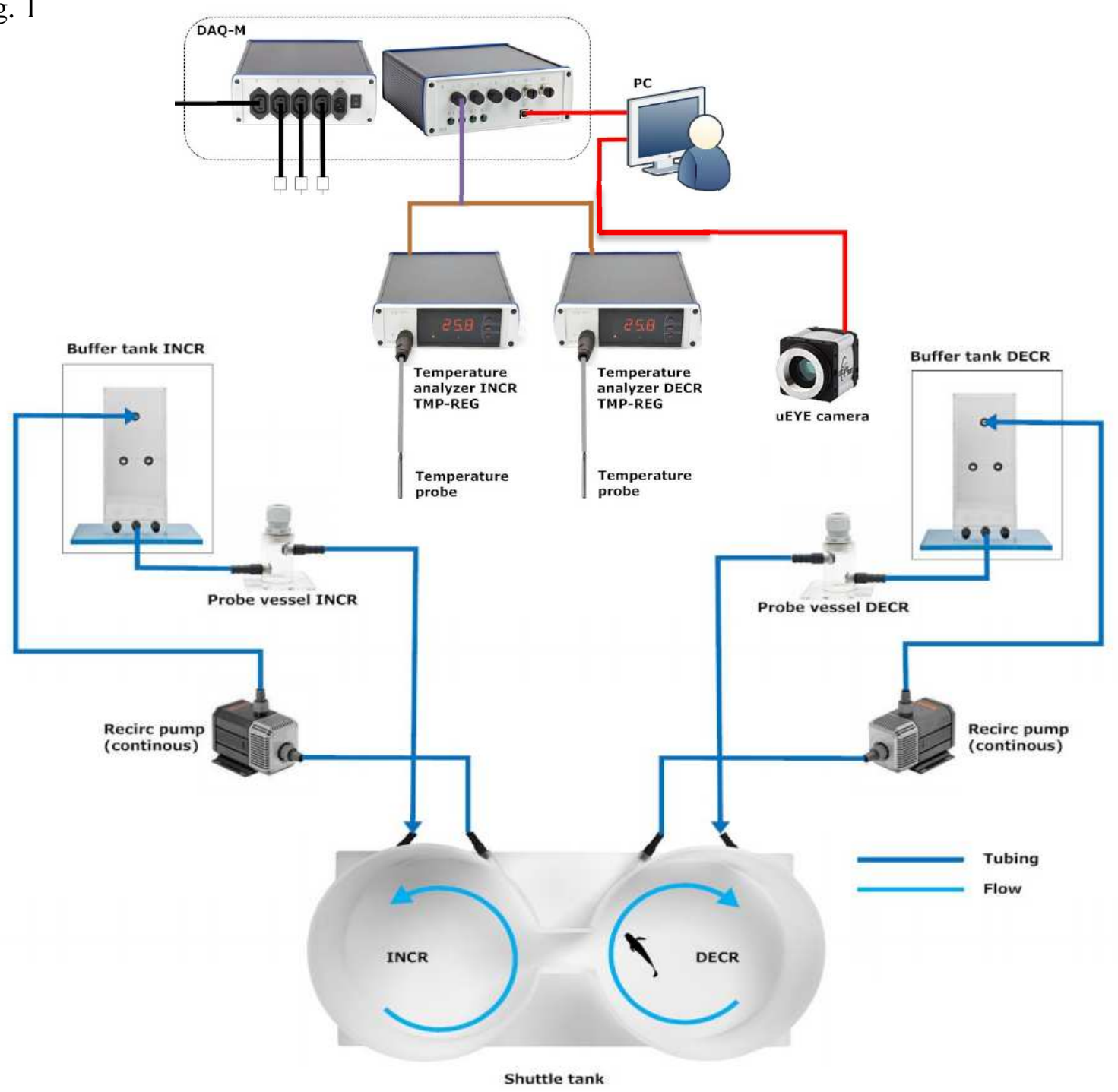


$752 \quad$ Fig. 2

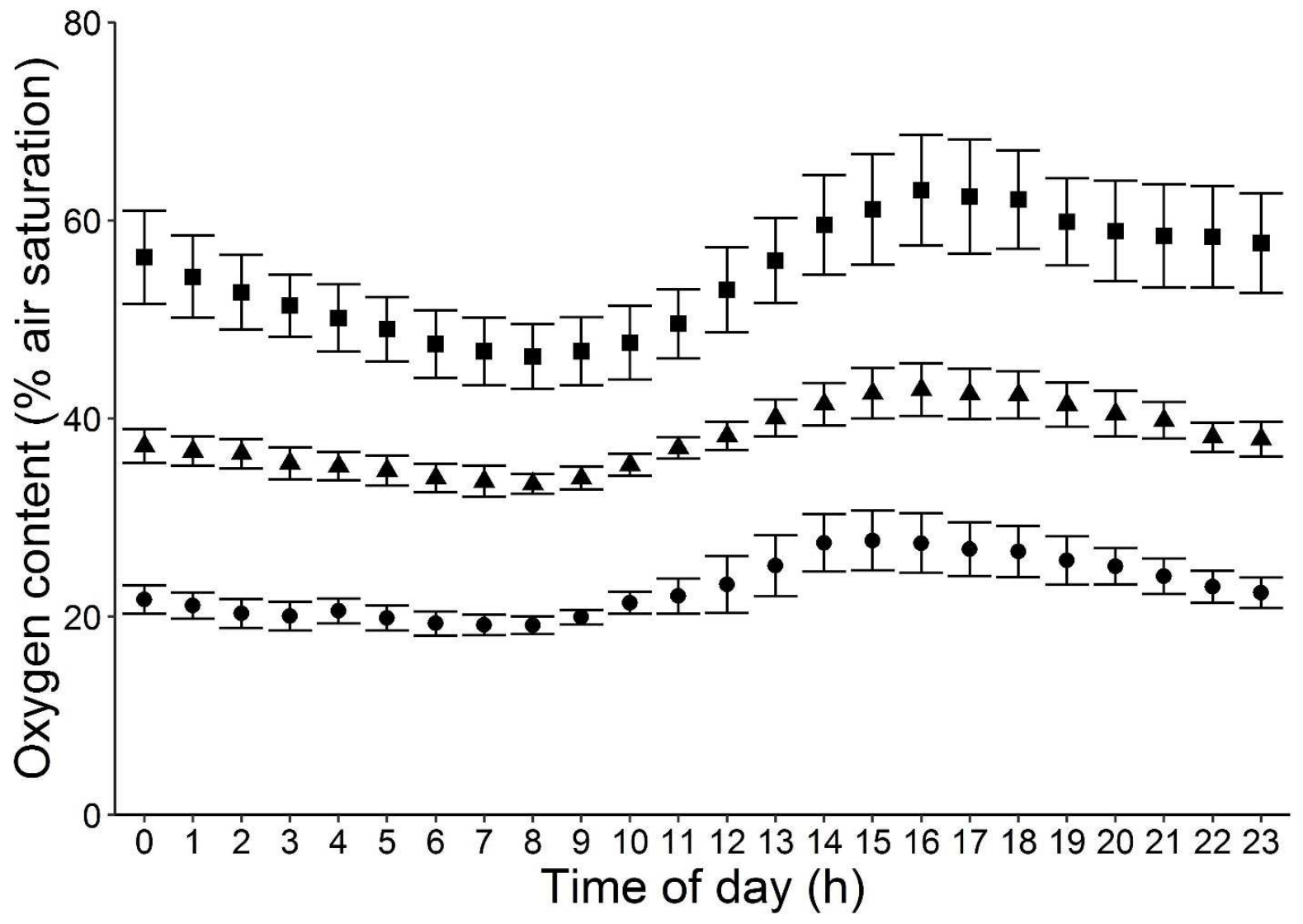


$755 \quad$ Fig.3

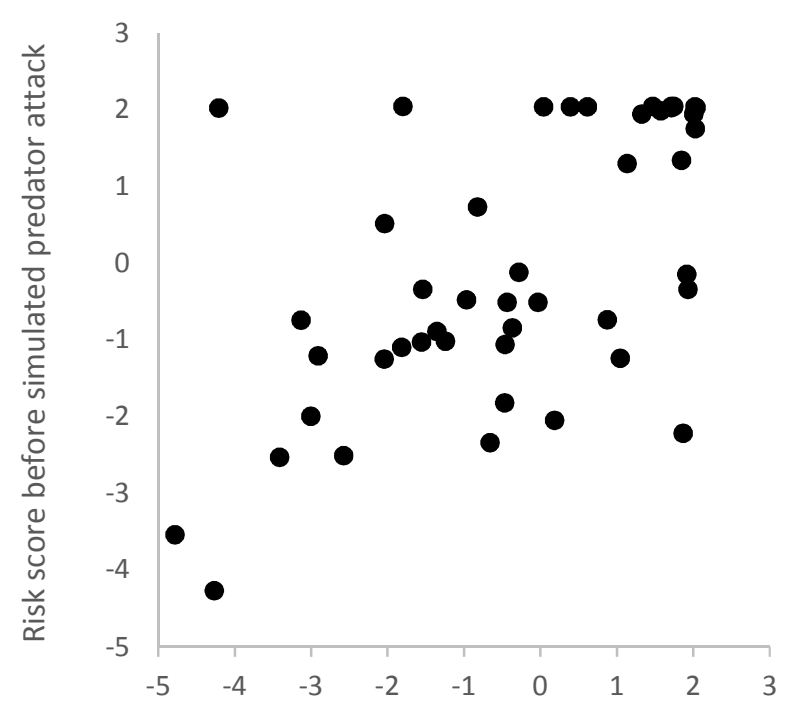


Fig. 4

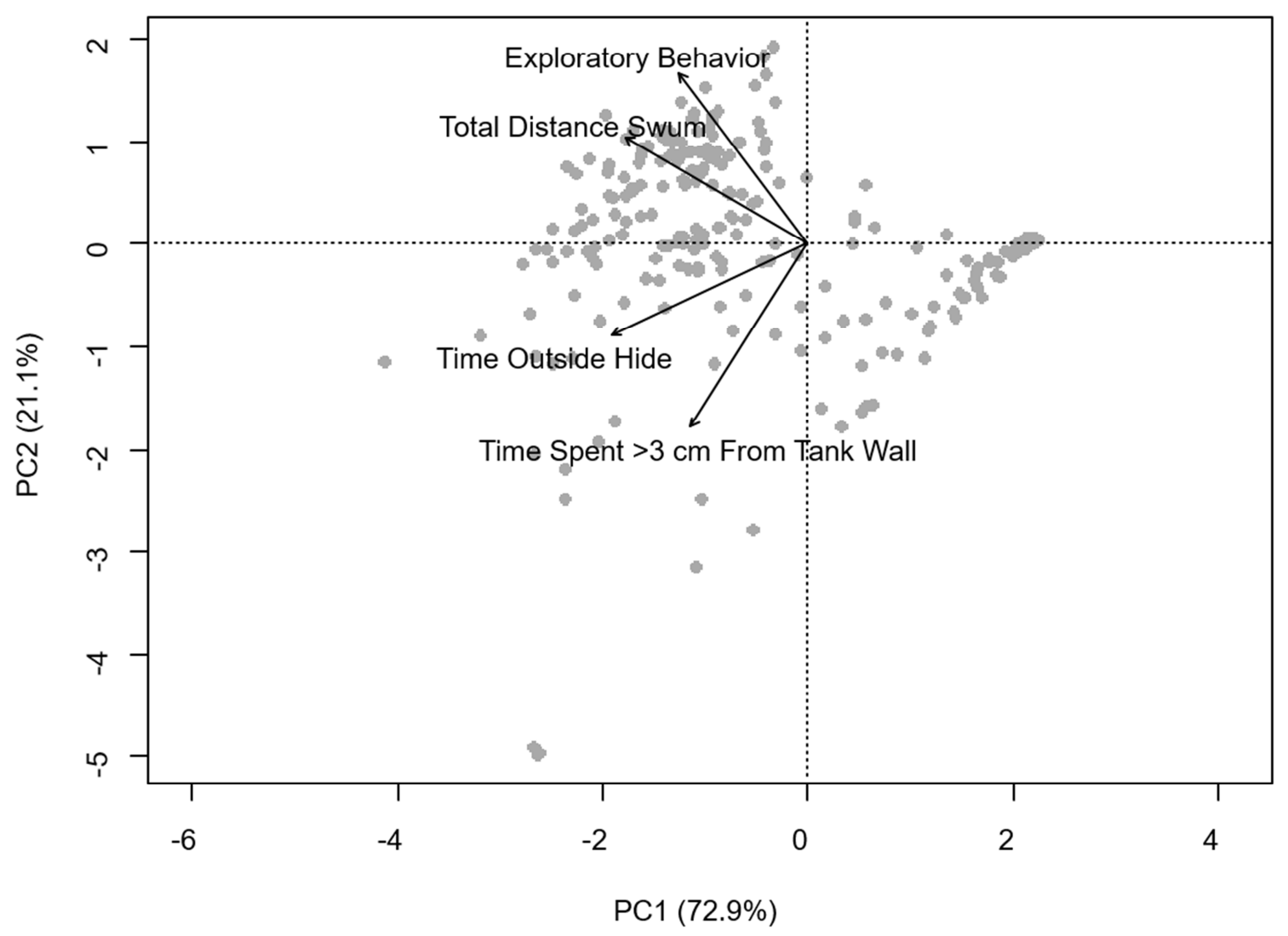


Fig. 5

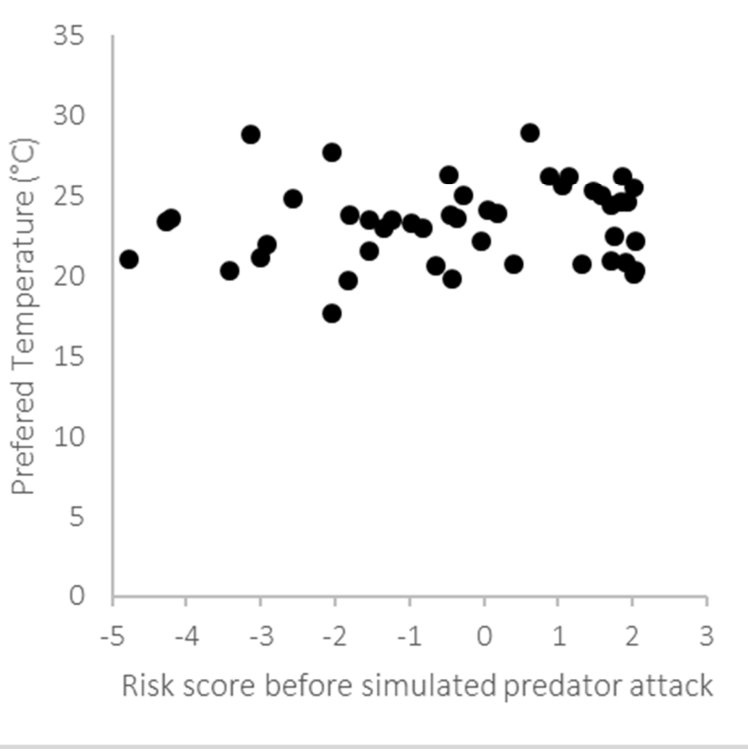

762 
Fig. 6

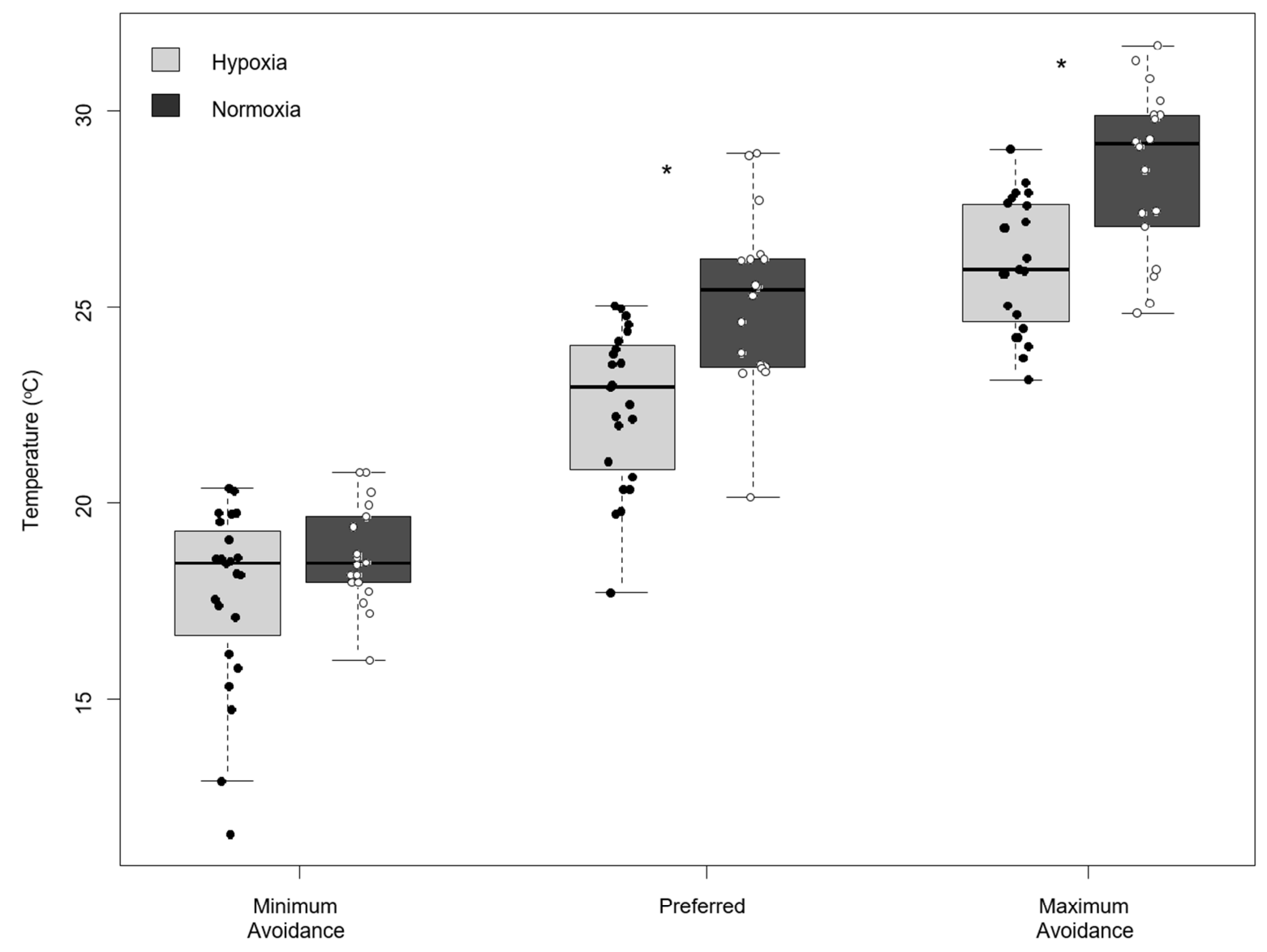

764 
767 S1: Individual risk scores at six time points (1-6 h) during the experimental trials.

\begin{tabular}{|c|c|c|c|c|c|c|}
\hline Fish ID & $1 \mathrm{~h}$ & $2 \mathrm{~h}$ & $3 \mathrm{~h}$ & $4 \mathrm{~h}$ & $5 \mathrm{~h}$ & $6 \mathrm{~h}$ \\
\hline 1 & -1.24014 & -1.01929 & -0.29183 & -0.71728 & -2.92198 & 0.878275 \\
\hline 2 & -0.36766 & -0.84201 & -0.28091 & -0.37193 & -0.49375 & -0.5977 \\
\hline 3 & 1.470792 & 2.041628 & 2.041628 & 2.039886 & 1.822815 & 1.368216 \\
\hline 4 & 0.614279 & 2.039886 & 2.032741 & 2.030116 & 2.011621 & 2.028458 \\
\hline 5 & 1.047317 & -1.23908 & -0.98387 & -1.11596 & -1.03552 & 1.938487 \\
\hline 6 & 1.869778 & -2.21454 & -1.97492 & -1.45466 & -1.16767 & 1.768579 \\
\hline 7 & -1.53672 & -0.3391 & 1.033922 & 1.048093 & -1.27248 & -2.15506 \\
\hline 8 & 2.02072 & 2.038017 & 2.041628 & 2.041628 & 1.98985 & 2.032908 \\
\hline 9 & 2.006879 & 1.945959 & 2.033046 & 2.041628 & 2.041628 & 2.038091 \\
\hline 10 & -2.03706 & 0.517648 & -1.06122 & -0.74753 & -0.97078 & -0.52529 \\
\hline 11 & 1.84825 & 1.340462 & -0.49717 & -0.99966 & -0.89706 & 2.036383 \\
\hline 12 & -2.90678 & -1.20857 & -0.51081 & 0.178411 & -0.5741 & -0.81217 \\
\hline 13 & -0.46708 & -1.822 & -0.72856 & -0.32671 & -0.64942 & -1.27571 \\
\hline 14 & -0.81942 & 0.731241 & -0.05791 & -0.06085 & -0.44548 & 1.961339 \\
\hline 15 & 1.577991 & 1.985304 & 1.577953 & 1.849408 & 2.041628 & 2.024501 \\
\hline 16 & 1.716406 & 2.041628 & 2.041628 & 2.039886 & 2.041628 & 2.041628 \\
\hline 17 & 1.748692 & 2.041628 & -0.7838 & -0.6456 & -0.34579 & -0.99233 \\
\hline 18 & -1.35366 & -0.89237 & -0.84133 & -0.60651 & -1.23786 & -1.47344 \\
\hline 19 & -2.57026 & -2.50933 & -2.30929 & -2.02762 & -2.02973 & -2.43801 \\
\hline 20 & -4.77903 & -3.53758 & -2.4798 & -2.24449 & -1.841 & -2.53464 \\
\hline
\end{tabular}




\begin{tabular}{|c|c|c|c|c|c|c|}
\hline 21 & 2.030726 & 1.755135 & 1.955545 & 1.400794 & -0.46135 & 1.581553 \\
\hline 22 & -0.4342 & -0.508 & -0.72668 & -1.24874 & -1.62321 & -1.57169 \\
\hline 23 & -2.04008 & -1.25063 & -0.8926 & -0.33608 & -0.95906 & -0.90959 \\
\hline 24 & 1.136097 & 1.297464 & 1.800259 & 1.98429 & 1.999731 & 1.292335 \\
\hline 25 & -3.1296 & -0.74399 & -1.22285 & -1.20383 & -0.99468 & -2.66997 \\
\hline 26 & 1.916089 & -0.14614 & -0.35523 & -0.67748 & -0.7492 & 1.914411 \\
\hline 27 & 1.325531 & 1.942087 & 1.939839 & 2.015663 & 1.99179 & 1.945593 \\
\hline 28 & -3.41132 & -2.52978 & -2.80264 & -2.78791 & 0.74474 & 1.166638 \\
\hline 29 & -0.28029 & -0.11605 & -1.01491 & -0.47011 & -1.07506 & 0.614046 \\
\hline 30 & 1.717589 & 2.02662 & 1.908673 & 1.422999 & 2.025376 & 2.033878 \\
\hline 31 & 0.185027 & -2.04683 & -0.82445 & -0.62927 & -0.59888 & -0.41729 \\
\hline 32 & -3.00043 & -1.99369 & -1.92818 & -2.27419 & -2.1021 & -2.35264 \\
\hline 33 & -0.03055 & -0.50932 & 0.481628 & -1.62286 & -0.75429 & 7.02E-05 \\
\hline 34 & -0.96672 & -0.47943 & -0.74039 & -0.98371 & -0.49463 & 0.54755 \\
\hline 35 & -1.79854 & 2.041628 & 2.041628 & 2.041628 & 2.041628 & 2.02 \\
\hline 36 & -4.20794 & 2.02512 & 2.041628 & 1.836824 & 2.041628 & 1.902274 \\
\hline 37 & -1.81506 & -1.09725 & -0.25572 & -0.43891 & -0.19925 & 0.371205 \\
\hline 38 & -0.46012 & -1.05972 & -0.68767 & -0.65785 & -1.02481 & 1.887353 \\
\hline 39 & 0.394581 & 2.039886 & 2.036363 & 2.036155 & 2.041628 & 2.03516 \\
\hline 40 & 2.041628 & 2.026095 & 2.041628 & 0.024636 & -0.50219 & -1.5041 \\
\hline 41 & -1.55122 & -1.02691 & -1.02174 & -0.94223 & -0.86846 & -2.008 \\
\hline 42 & 0.043736 & 2.036162 & 2.041628 & 2.041628 & 2.041628 & 1.477448 \\
\hline 43 & -4.26439 & -4.26966 & -0.79606 & -0.05452 & -0.51754 & -0.9859 \\
\hline
\end{tabular}




$\begin{array}{lllllll}44 & -0.65465 & -2.33901 & -1.61881 & -1.18413 & -1.08189 & -1.63695 \\ 45 & 0.874935 & -0.73507 & -0.26815 & -0.15622 & -0.22665 & 1.176059 \\ 46 & 1.933865 & -0.34153 & 0.704742 & 0.095776 & 0.486349 & 2.01426\end{array}$

768

769 
S2: Results from the principal component analysis with loadings and proportion of variances

771 explained by the first four principal components.

\begin{tabular}{lcccc}
\hline Variables and statistics & PC1 & PC2 & PC3 & PC4 \\
\hline Total Distance Swum & -0.5342435 & 0.3088472 & -0.6803779 & 0.39532674 \\
Time outside of Hide & -0.5533894 & -0.2577944 & -0.1358676 & -0.78028339 \\
Time away from Wall $(>3 \mathrm{~cm})$ & -0.4419678 & -0.6849186 & 0.3176074 & 0.48443423 \\
Exploratory Behaviour & -0.4615285 & 0.6074882 & 0.6463370 & 0.01407395 \\
Standard Deviation & 1.7072 & 0.9183 & 0.40333 & 0.28209 \\
Proportion of Variance & 0.7286 & 0.2108 & 0.04067 & 0.01989 \\
Cumulative Proportion & 0.7286 & 0.9394 & 0.98011 & 1.00000 \\
\hline
\end{tabular}

772 


\section{Highlights:}

- Shy-bold behavioural phenotypes are consistent after aerial predator attack

- Individual preferred and avoidance temperatures vary substantially

- Shy-bold phenotypes are not related to preferred temperature

- Oxygen availability may influence thermoregulatory behaviours 